\title{
Performance evaluation of manual operated single wheel weeder for jute crop
}

R. K. Naik, S. K. Jha, S. Sarkar and A. K. Ghorai

Received : 10.10.2017; Revised : 07.02.2018; Accepted : 16.02.2018

See end of the Paper for authors' affiliation

Correspondence to :

R. K. Naik

ICAR-Central Research Institute for Jute and Allied

Fibres, Barrackpore, Kolkata

(W.B.) India

Email : ranjanagrieng@

rediffmail.com
- ABSTRACT : An experiment was conducted to evaluate the field performance of developed manual operated single wheel weeder at ICAR-Central Research Institute for Jute and Allied Fibres, Barrackpore, Kolkata. Various parameters such as field capacity, weeding efficiency, draft requirement and performance index of the weeder was measured during the test. The developed weeder can work upto 5.0-6.0 cm depth of operation with actual field capacity of $0.026 \mathrm{ha} / \mathrm{h}$ and field efficiency of 76.7 per cent. The draft requirement was $29.7 \mathrm{~kg}$ for $18 \mathrm{~cm}$ width of weeder. The weeding efficiency of the machine was found to be 81.65 per cent with performance index of 1123.01. The experiment also revealed that the weeding time requirement for single wheel weeder is much less than the manual weeding. It was easy to operate and most importantly involved less human drudgery during its operation.

- KEY WORDS : Weeder, Weeding efficiency, Field capacity, Field performance

-HOW TO CITE THIS PAPER : Naik, R.K., Jha, S.K., Sarkar, S. and Ghorai,A.K. (2018). Performance evaluation of manual operated single wheel weeder for jute crop. Internat. J. Agric. Engg., 11(1): 49-53, DOI: 10.15740/HAS/IJAE/11.1/49-53. 